Atıf İçin: Ertap H, Karabulut M, 2021. Bridgman Tekniği ile Büyütülen Saf ve Bor Katkılı InSe Tek Kristallerinin Morfolojik ve Optik Özelliklerinin Araştırılması. Iğdır Üniversitesi Fen Bilimleri Enstitüsü Dergisi, 11(2): 1090-1101.

To Cite: Ertap H, Karabulut M, 2021. Investigation of Morphological and Optical Properties of Undoped and Boron Doped InSe Single Crystals Grown by Bridgman Technique. Journal of the Institute of Science and Technology, 11(2): 1090-1101.

\title{
Bridgman Tekniği ile Büyütülen Saf ve Bor Katkılı InSe Tek Kristallerinin Morfolojik ve Optik Özelliklerinin Araştırılması
}

\author{
Hüseyin ERTAP ${ }^{1 *}$, Mevlüt KARABULUT ${ }^{2}$
}

ÖZET: Bridgman tekniği ile büyütülen saf, \% 0.1 ve \% 0.5 bor katkı1ı InSe tek kristallerinin morfolojik ve optik soğurma özellikleri araştırıldı. Saf, \% 0.1 ve \% 0.5 bor katkılı InSe tek kristallerinin morfolojik ve optik soğurma özellikleri AFM, SEM ve UV-Vis spektrofotometre teknikleri ile araştırıldı. SEM analizleri geniş yüzeyli yüksek kalitede InSe tek kristallerinin stokiyometrik eriyikten büyüdügünü gösterdi. Optik soğurma spektrumlarının analizinden saf ve \% 0.1 bor katk11 InSe tek kristallerine oranla \% 0.5 bor katk1l InSe tek kristalinin eksiton pikinin genişlediği görüldü. Ayrıca, bor katkısı sonucu soğurma şiddetinin azaldığı ve soğurma kenarının daha uzun dalga boyuna doğru kaydığı görüldü. Optik soğurma ölçümlerinden, hem saf hem de bor katkılı InSe tek kristallerinin direkt yasak enerji bant aralığına sahip olduğu gözlendi. Ayrıca, saf InSe tek kristalinin yasak enerji bant aralığına oranla bor katkılı InSe tek kristallerinin yasak enerji bant aralıklarının katkı oranına bağlı olarak azaldığı görüldü.

Anahtar Kelimeler: Bridgman, saf ve bor katıl1 InSe tek kristalleri, optik soğurma.

\section{Investigation of Morphological and Optical Properties of Undoped and Boron Doped InSe Single Crystals Grown by Bridgman Technique}

\begin{abstract}
Morphological and optical absorption properties of undoped, 0.1 at $\%$ and 0.5 at $\%$ boron doped InSe single crystals grown by Bridgman technique were investigated. Morphological and optical absorption properties of undoped, 0.1 at $\%$ and 0.5 at $\%$ boron doped InSe single crystals have been investigated by AFM, SEM and UV-Vis spectrophotometer techniques. SEM analysis showed that high quality InSe single crystals with large surface area were grown from the stoichiometric melt. From the analysis of optical absorption spectra showed that the exciton peak in 0.5 at $\%$ boron doped InSe single crystal expanded by relative to the undoped and 0.1 at $\%$ boron doped InSe single crystals. In addition, it was seen that the intensity of absorption decreased and absorption edge shifted to longer wavelengths as a result of boron doping. Optical absorption measurements showed that both undoped and boron doped InSe single crystals had direct forbidden band energies. Also, energy band gaps in boron doped InSe single crystals decreased with increasing boron concentration relative to the energy band gap of undoped InSe single crystal.
\end{abstract}

Keywords: Bridgman, undoped and boron doped InSe single crystals, optical absorption.

\footnotetext{
${ }^{1}$ Hüseyin ERTAP (Orcid ID: 0000-0003-3896-6188), Kafkas Üniversitesi, Fen Edebiyat Fakültesi, Fizik Bölümü, Kars, Türkiye

${ }^{2}$ Mevlüt KARABULUT (Orcid ID: 0000-0002-0227-318X), Gebze Teknik Üniversitesi, Temel Bilimler Fakültesi, Fizik Bölümü, Gebze, Kocaeli, Türkiye

*Sorumlu Yazar/Corresponding Author: Hüseyin ERTAP, e-mail: huseyinertap@kafkas.edu.tr Bu çalışma Hüseyin Ertap'ın Doktora Tezinin bir kısmından üretilmiştir.
} 


\section{GíRiș}

Tabakalı yarıiletken bir bileşik olan İndiyum Selenit (InSe) kristali, GaSe, GaTe ve GaS gibi yariiletken bileşikleri içeren $\mathrm{A}^{\mathrm{III}} \mathrm{B}^{\mathrm{VI}}$ yariiletken ailesinin önemli bir üyesidir (Gouskov ve ark., 1982; Ertap ve ark., 2011; Yüksek ve ark., 2012; Ertap ve ark., 2015; Ertap ve ark., 2016; Ertap, 2018). InSe kristallerinde tabakalar arasında zayıf Van-der Waals bağı varken, tabakalar içinde atomlar birbirlerine güçlü kovalent bağlarla bağlanmıştır ve bu kristallerde gözlemlenen anizotropi bu durumdan kaynaklanmaktadır (Olguin ve ark., 2003; Zhirko ve ark., 2007; Ertap ve Karabulut, 2019). InSe kristalinde her bir paket sırasıyla Se-In-In-Se şeklinde sıkı paketlenmiş dört alt tabakadan oluşur ve bir In atomu üç Se atomu tarafından çevrelenerek tetragonal bağ oluşturur (Blasi ve ark., 1983; Zhirko ve ark., 2007). Eksiton seviyelerine sahip olan InSe kristali koyu siyah renktedir ve kolayca tabakalarına ayrılabilir (Cingolani ve ark., 1985). InSe yarıiletken bileşiği tek kristal olarak genellikle stokiyometrik ve stokiyometrik olmayan eriyiklerden Bridgman-Stockbarger yöntemi ile elde edilmektedir (Gouskov ve ark., 1982; Blasi ve ark., 1982; Gurbulak ve ark., 1999; Ertap ve Karabulut, 2019). BridgmanStockbarger yöntemine ek olarak, farklı boyutlardaki InSe yarıiletken bileşiklerini büyütmek için birçok yöntem/teknik kullanılmaktadır. Bu yöntem/tekniklerden bazıları Czochralski (Chevy ve ark., 1978), Moleküler Demet Epitaksi (Emery ve ark., 1989), Kimyasal Banyo Depolama (CBD) (Asabe ve ark., 2008), Elektrodepozisyon (Gopal ve ark., 2005), Termal Buharlaştırma (Viswanathan ve ark., 2004) ve Modifiye Kimyasal Banyo Depolama (M-CBD) (Pathan ve ark., 2005) olarak bilinmektedir. $\mathrm{A}^{\mathrm{III}} \mathrm{B}^{\mathrm{VI}}$ yariiletken kristal ailesinin bir bireyi olan InSe kristalinin üç politipinin mevcut olduğu bilinmektedir. Bu politipler $\gamma$-InSe, $\varepsilon$-InSe ve $\beta$-InSe olarak bilinir. Sirasıyla $\gamma, \varepsilon$ ve $\beta$ politiplerinin uzay grupları $C_{3 v}^{5}(R 3 m), D_{3 h}^{1}(P \overline{6} m 2), D_{6 h}^{4}\left(P 6_{3} / m m c\right)$ olarak belirtilmiştir (Chevy ve ark., 1977; Gouskov ve ark., 1982; Blasi ve ark., 1982; Blasi ve ark., 1983; Blasi ve ark., 1990; Rushchanskii, 2004; Ertap ve Karabulut, 2019). InSe yariiletken kristalleri genellikle $\gamma$-politipi ile rombohedral kristal yapıya sahip iken (Gouskov ve ark., 1982) $\varepsilon$ ve $\beta$ politipleri hekzagonal yapıya sahiptir (Blasi ve ark., 1983; Blasi ve ark., 1990; Ertap ve Karabulut, 2019). Rombohedral yapıya sahip olan $\gamma$-InSe politipinin örgü

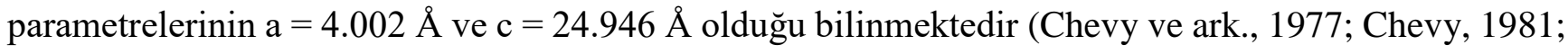
Blasi ve ark., 1983; Blasi ve ark., 1990; Ertap ve Karabulut, 2019). Ayrıca, hekzagonal yapıda sahip olan $\beta$-InSe politipinin örgü parametreleri $\mathrm{a}=4.005 \AA$ ve $\mathrm{c}=16.640 \AA$ (Blasi ve ark., 1983) iken $\varepsilon$-InSe politipinin örgü parametreleri ise $\mathrm{a}=4.00 \AA$ ve $\mathrm{c}=16.70 \AA \AA$ olarak verilmektedir (Blasi ve ark., 1990).

InSe yarıiletken kristalinin direkt ve indirekt yasak enerji bant aralığ değerleri sirasıyla $1.3 \mathrm{eV}$ ve 1.25 eV olarak rapor edilmiştir (Segura ve ark., 1983; Ertap ve ark., 2015) ve bu özellik InSe kristalini güneş pili uygulamaları için önemli bir materyal yapmaktadır (Segura ve ark., 1983; Kobbi ve Kesri, 2004). InSe yarıiletken kristalinin fotovoltaik uygulama alanlarında ve heteroeklem aygitlarında, Schottky diyotlarda, kapasitörlerde, gaz sensörlerinde, anahtarlama devrelerinde, detektörlerde ve mikrobataryalar gibi mikro aygıtlarda, ticari ve endüstriyel alanlarda potansiyel uygulamaları mevcuttur (Di Giulio ve ark., 1983; Segura ve ark., 1983; Parlak ve ark., 1995; Kobbi ve Kesri, 2004; Viswanathan ve ark., 2004; Mustafa ve ark., 2010). Büyütme koşulları, büyütme parametreleri ve katkı elementine bağlı olarak InSe yariiletken kristali p ve n tipi olarak büyütülebildiğinden oldukça ilgi çekici bir materyaldir (Ikari ve ark., 1981). InSe kristalleri uzun yıllardır saf kristal olarak büyütülmenin yanı sıra Er, Zn, Ho, Dy, Gd, Mn, Sn, As, Ag, N ve son zamanlarda B atomları ile farklı oranlarda katkılanarak bu katkıların elektrik, optik, fotolüminesans, vb. gibi özelliklerine etkisi araştırılmıştır (Ikari ve ark., 1981; Gürbulak ve ark., 1998; Gürbulak, 1999; Gurbulak ve ark., 1999; Shigetomi ve Ikari, 2003; Gürbulak, 2004; Deniz, 2004; Lashkarev ve ark., 2007; Bacığlu ve ark., 2014; Gürbulak ve ark., 2014; Ertap ve ark., 2015; Gürbulak ve ark., 2016; Ertap ve Karabulut, 2019). InSe, InSe:Er ve InSe:Ho 
kristallerinin optik soğurma ölçümleri 10-320 K sıcaklık aralı̆ı̆ında yapılmıştır. Yapılan ölçümler sonucunda InSe kristalinin $10 \mathrm{~K}, 200 \mathrm{~K}$ ve $300 \mathrm{~K}$ sicaklıklarındaki direkt yasak enerji bant aralıkları sirasıyla $1.339 \mathrm{eV}, 1.289 \mathrm{eV}$ ve $1.256 \mathrm{eV}$, InSe:Er kristalinin aynı sicaklık değerlerindeki direkt yasak enerji bant aralıkları sirasiyla $1.338 \mathrm{eV}, 1.288 \mathrm{eV}$ ve $1.253 \mathrm{eV}$ (Gurbulak ve ark., 1999) ve InSe:Ho kristalinin $10 \mathrm{~K}, 100 \mathrm{~K}, 200 \mathrm{~K}$ ve $280 \mathrm{~K}$ sıcaklıkları için direkt yasak enerji bant aralıkları sırasıyla 1.332 $\mathrm{eV}, 1.313 \mathrm{eV}, 1.283 \mathrm{eV}$ ve $1.255 \mathrm{eV}$ olarak hesaplanmıştır (Gürbulak ve ark., 1998). n-InSe ve nInSe:Dy kristallerinin optik soğurma ölçümleri sıcaklığın bir fonksiyonu olarak gerçekleştirilmiş ve yapılan ölçümler sonucunda, $10 \mathrm{~K}$ ve $300 \mathrm{~K}$ 'deki direkt yasak enerji bant aralıkları sirasıyla n-InSe kristali için $1.350 \mathrm{eV}$ ve $1.267 \mathrm{eV}$, n-InSe:Dy kristali için ise $1.344 \mathrm{eV}$ ve $1.263 \mathrm{eV}$ olarak bulunmuştur (Gürbulak, 1999). Yapılan bir başka çalışmada ise $10 \mathrm{~K}$ ve $300 \mathrm{~K}$ 'deki direkt yasak enerji bant aralıkları sırasıyla InSe kristali için $1.343 \mathrm{eV}$ ve $1.259 \mathrm{eV}$ ve InSe:Gd kristali için ise $1.335 \mathrm{eV}$ ve $1.253 \mathrm{eV}$ olarak bulunmuştur (Gürbulak, 2004). InSe tek kristalinin elektrik alan altındaki soğurma ölçümleri sıcaklığın bir fonksiyonu olarak gerçekleştirilmiş ve uygulanan $5 \mathrm{kV} / \mathrm{cm}$ elektrik alan altında, soğurma spektrumu şiddetinin azaldığı ve soğurma kenarının uzun dalga boyuna doğru kaydığı gözlemlenmiştir (Ateş ve ark., 2003).

$\mathrm{Bu}$ çalışmada, Bridgman tekniği ile büyütülen saf, \% 0.1 ve \% 0.5 bor katkılı InSe tek kristallerinin morfolojik ve optik özellikleri Atomik Kuvvet Mikroskobu (AFM), Taramalı Elektron Mikroskobu (SEM) ve UV-Vis yöntemleri ile araştırıldı.

\section{MATERYAL VE METOT}

Saf ve bor katkılı InSe tek kristallerinin büyütme işleminden önce bu kristalleri oluşturan bileşiklerin sentez işleminin titizlikle gerçekleştirilmesi gerekmektedir. Saf In (\% 99.999), Se (\% 99.999) ve B (\% 99.7) elementlerinden stokiyometrik oranlarda hazırlanan bileşimler çok titizlikle temizlenmiş kuvars ampullere doldurularak $10^{-4} \mathrm{Hg} \cdot \mathrm{mm}$ basınçta kapatılmıştır. In, Se ve B elementleri ile stokiyometrik oranlarda doldurularak kapatılmış olan kuvars ampullerin bulunduğu sentezleme firınının sıcaklı̆g $25{ }^{\circ} \mathrm{C} /$ saat 1sıtma hızı ile 24 saatte $600{ }^{\circ} \mathrm{C}$ sicaklığına getirildi. $600{ }^{\circ} \mathrm{C}$ sicaklı̆̆ında ergimiş halde bulunan elementlerin etkileşmesi sonucunda saf ve bor katkılı InSe yariletken bileşiklerinin oluşumu gerçekleşir. Bu sıcaklıklarda ampullerin titreştirilmesi büyütülmek istenen yarıiletken bileşiğin homojen olmasını sağladığından dolayı her sıcaklık artışında ampuller çalkalanmış/titreştirilmiştir. İçerisinde saf ve farklı oranlarda bor katkılı InSe yariletken bileşiklerinin bulunduğu kuvars ampuller $600{ }^{\circ} \mathrm{C}$ sicaklı̆ğında 30 dakikalık periyotlarda 6 saat boyunca çalkalanarak/titreştirilerek bekletildi. Bu sıcaklık değerinden sonra sentezleme firının sıcaklığı 25 ${ }^{\circ} \mathrm{C} /$ saat hızı ile $800{ }^{\circ} \mathrm{C}$ sıcaklı̆ı̆ına çıkarıldı. Bu son sıcaklıkta ampulde bulunan saf ve bor katkılı InSe yarıiletken bileşiklerinin sıvı durumda olduğu gözlemlendi. Bu sıcaklık değerinde 30 dakikalık periyotlarda 12 saat boyunca kuvars ampuller çalkalanarak/titreştirilerek bekletildi. Çalkalama/Titreştirme işleminden sonra saf ve bor katkılı InSe yariletken bileşikleri $800^{\circ} \mathrm{C}$ sıcaklı̆̆ında 48 saat bekletildi. Son olarak saf ve bor katkılı InSe yariletken bileşiklerinin sentezlendiği firının sıcaklığ $1800^{\circ} \mathrm{C}$ sıcaklığından $25^{\circ} \mathrm{C} /$ saat hızı ile oda sıcaklığına 32 saatte düşürüldü. Bütün bu işlemler sonucunda saf ve bor katkılı InSe yariletken bileşiklerinin sentezi gerçekleştirilmiş oldu. Sentezleme işlemi gerçekleştirilen saf InSe yariiletken bileşiğinin doldurulmuş olduğu kuvars ampul merkezi olacak şekilde Bridgman firınına yerleştirildi. Saf InSe yariiletken bileşiğinin bulunduğu kuvars ampulün Bridgman firınına yerleştirilmesi işleminden sonra Bridgman fırınının sıcaklığı 9 saat içerisinde $660{ }^{\circ} \mathrm{C}$ sıcaklık değerine çıkarıldı ve bu sıcaklıkta saf InSe yariiletken bileşiği eriyik halde olduğu gözlemlendi. Termal dengenin sağlanması için Bridgman firın bu sıcaklıkta 15 saat bekletildi. Bu işlemden sonra Bridgman firınının $2 \mathrm{~mm} / \mathrm{saat}$ hızıyla dikey hareketi gerçekleştirildi. Saf InSe yariletken tek kristalinin 
büyütülme işlemi için gerekli olan Bridgman firınının hareketinin tamamlanmasından sonra Bridgman firını oda sıcaklığına kadar soğutuldu. Saf InSe yarıiletken tek kristali için izlenen bu süreç bor katkılı InSe yariiletken tek kristalleri içinde gerçekleştirilmiştir. Büyütme işlemi gerçekleştirilen saf ve bor katkılı InSe tek kristalleri yaklaşık olarak $18 \mathrm{~mm}$ çapa ve $40 \mathrm{~mm}$ uzunluğa sahiptirler. Bridgman tekniği ile büyütülen saf ve bor katkılı InSe tek kristalleri ayna gibi parlak, pürüzsüz ve temiz yüzeylere sahip olduklarından dolayı herhangi bir kimyasal işleme ve parlatma gibi bir işleme gerek yoktur. Tabakalı yapılarından dolayı saf ve bor katkılı InSe tek kristalleri neşter/jilet yardımıyla kolayca tabakalara ayrılıp deneyler için gerekli numuneler hazırlanabilmektedir. Büyütülen saf ve bor katkılı InSe tek kristallerinden analizler için $20 \pm 2 \mu \mathrm{m}$ kalınlığında ve $5 \times 5 \mathrm{~mm}^{2}$ boyutlarında örnekler hazırlandı. Bu çalışmada, Bridgman yöntemi ile büyütülen saf ve bor katkılı InSe tek kristallerinin bor oranları İndüktif Eşleşmiş Plazma (Inductively Coupled Plasma-ICP) yöntemi ile belirlendi. ICP ölçümleri analizi sonucunda çalışılan numuneler saf, \% 0.1 ve \% 0.5 bor katkılı InSe tek kristalleri olarak adlandırıldı.

Saf, \% 0.1 ve \% 0.5 bor katk1lı InSe tek kristallerinin yüzey morfolojisi PSIA marka XE-100 model Atomik Kuvvet Mikroskobu ile $2.00 \mathrm{~Hz}$ tarama hızı ve 1024x1024 piksel çözünürlük parametreleriyle ve FEI marka Nova Nanosem 430 model Taramalı Elektron Mikroskobu ile $10 \mathrm{kV}$ hızlandırma voltajında, $10.000 \mathrm{X}, 5.000 \mathrm{X}$ ve $1.000 \mathrm{X}$ büyütme oranları ile gerçekleştirildi. Bu analizlere ek olarak, optik soğurma ölçümleri ise Perkin-Elmer Lambda 25 UV-Vis spektrofotometre ile 190-1100 $\mathrm{nm}$ dalga boyu aralığında $0.5 \mathrm{~nm}$ 'lik adımlarla oda sıcaklığında gerçekleştirildi.

\section{BULGULAR VE TARTIŞMA}

Saf, $\% 0.1$ ve $\% 0.5$ bor katk1lı InSe tek kristallerinin morfolojik özellikleri AFM ve SEM ölçümleri ile gerçekleştirildi. Saf, $\% 0.1$ ve $\% 0.5$ bor katkılı InSe tek kristallerinin üç boyutlu ve tek boyutlu AFM görüntüleri sırasıyla Şekil 1, Şekil 2 ve Şekil 3'te verilmektedir.
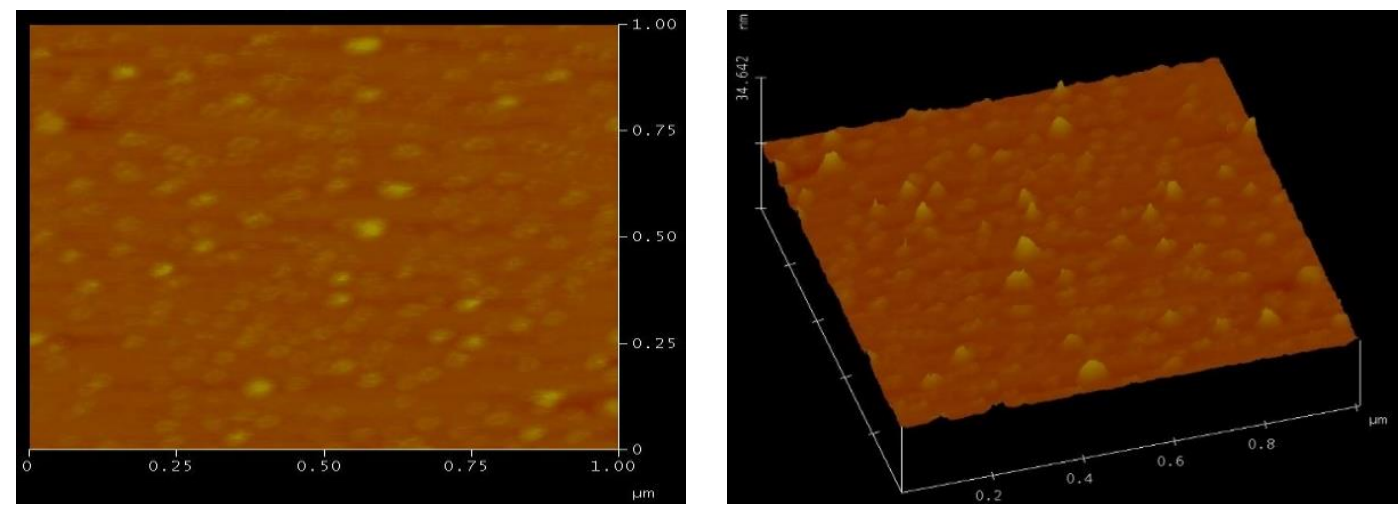

Şekil 1. Saf InSe tek kristalinin AFM görüntüleri.
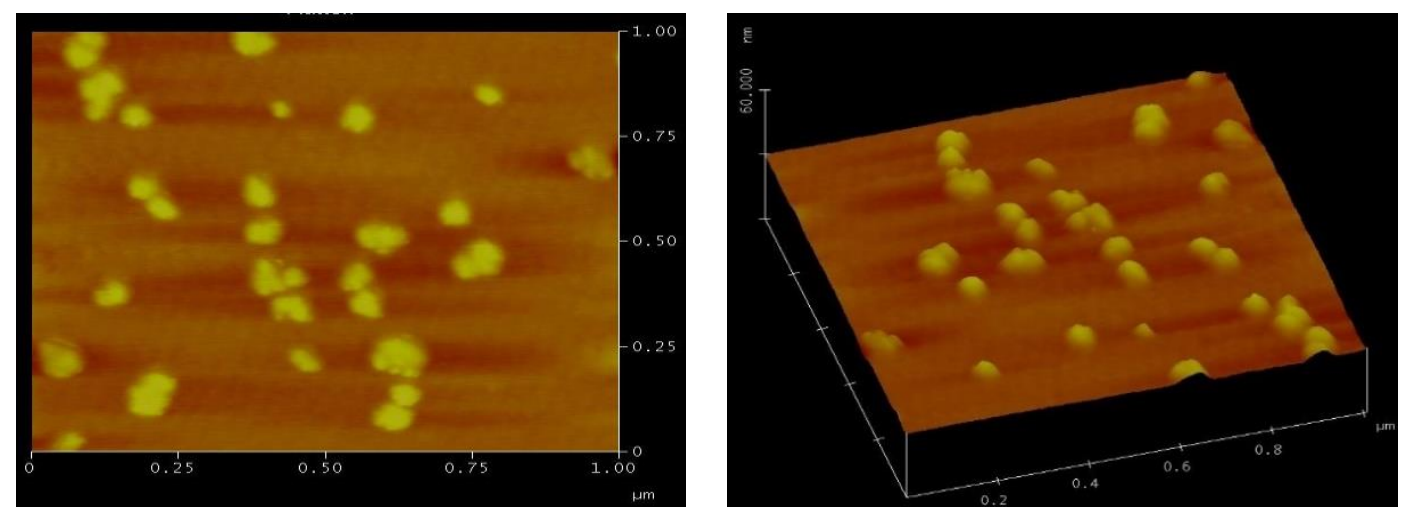

Şekil 2. \% 0.1 bor katk1lı InSe tek kristalinin AFM görüntüleri. 

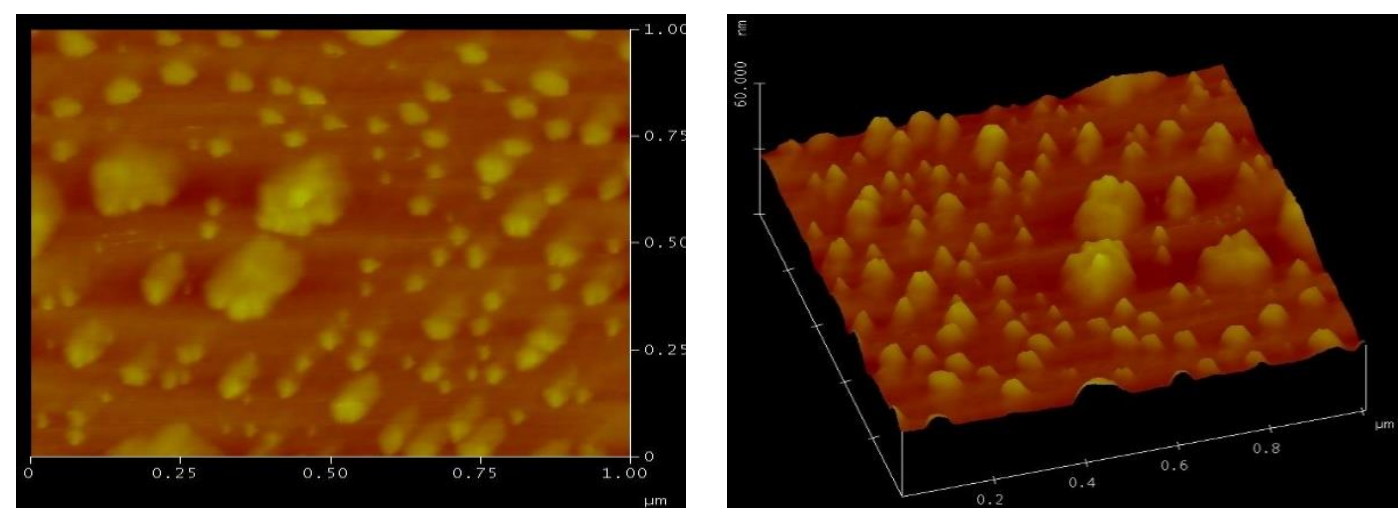

Şekil 3. $\% 0.5$ bor katk1lı InSe tek kristalinin AFM görüntüleri.

Saf, \% 0.1 ve \% 0.5 bor katkılı InSe tek kristallerinden hazırlanan örneklerin yüzeyleri tamamlanmış bağa sahiptirler. Bu çalışmada kullanılan Saf, \% 0.1 ve \% 0.5 bor katkılı InSe tek kristallerinin AFM görüntülerinde çok az tepe ve çukurlar görülmektedir. Şekil 1, Şekil 2 ve Şekil 3 'te sirasıyla saf, \% 0.1 ve \% 0.5 bor katkılı InSe tek kristallerinin (0001) yüzeyinin AFM görüntüleri verilmektedir. Saf, \% 0.1 ve \% 0.5 bor katkılı InSe tek kristallerinin AFM analizlerinden sirasıyla tanecik yükseklikleri $1.752 \mathrm{~nm}, 2.341 \mathrm{~nm}$ ve $4.107 \mathrm{~nm}$ ve Rms pürüzsüzlükleri $\left(\mathrm{R}_{\mathrm{q}}\right)$ ise $0.491 \mathrm{~nm}, 0.940 \mathrm{~nm}$ ve $1.627 \mathrm{~nm}$ olarak hesapland1. Bu kristallerin XRD analizlerinden hesaplanan parçacık boyutunun bor katkı oranına bağlı olarak azaldığı (Ertap ve Karabulut, 2019) ve parçacık boyutunun azalmasına bağlı olarak yüzey pürüzsüzlüğü ve tanecik yüksekliğinin artması beklenen bir sonuçtur. Bu sonuçlardan da görüldüğü gibi bor katkı oranına bağlı olarak tanecik yüksekliği, ortalama pürüzsüzlük ve Rms pürüzsüzlük değerlerinin arttığı görülmektedir. Yine de bu değerlerin oldukça küçük olması büyütülen saf, \% 0.1 ve \% 0.5 bor katkılı InSe tek kristallerinin AFM görüntülerinden alınan kesitlerde, tepe ve çukurların az olması büyütülen kristallerin kalitesini, politipizmden kaynaklanan kusurların ve örgü kusurlarının az olduğunu göstermektedir. Bu çalışmada saf, \% 0.1 ve \% 0.5 bor katkılı InSe tek kristallerinin oda sıcaklığındaki optik soğurma ölçümlerinde eksiton soğurulması durumu açıkça görülmektedir ve bu durum da büyütülen tek kristallerin örgü kusurlarının az olduğunu göstermektedir. AFM görüntülerinde görülen tepe ve çukurlardan daha önce yapılan çalışmalarda da bahsedilmiştir (Uosaki ve Koinuma, 1993; Hirohata ve ark., 2006; Khandozhko ve ark., 2014). Atomik ölçekte InSe kristalindeki ayna yüzeylerde görülen düzensizlikler, dislokasyonlar ve politiplerden kaynaklanmaktadır (Blasi ve ark., 1985; Uosaki ve Koinuma, 1993; Balitskii ve ark., 2004; Bakhtinov ve ark., 2007; Khandozhko ve ark., 2014). Ayrıca, bir başka çalışmada ise InSe tek kristallerinde düzensizliğin azalması ile mükemmel tabakalı kristallerin oluşabileceği ve böylece eksiton oluşumunun gerçekleşeceği, ancak mükemmel olmayan InSe tek kristallerinde ise eksiton durumunun gözlemlenemeyeceği belirtilmiştir (Khandozhko ve ark., 2014). Saf, \% 0.1 ve \% 0.5 bor katkılı InSe tek kristallerinin birkaç farklı büyütme oranı kullanılarak elde edilen SEM görüntüleri sırasıyla Şekil 4, Şekil 5 ve Şekil 6'da verilmektedir.

Yapılan analizler sonucunda saf, \% 0.1 ve \% 0.5 bor katkılı InSe tek kristallerinin farklı kesitlerinden alınan birbirlerine oldukça yakın olan kristalit boyutlarının sırasıyla 140-62 nm, 120-58 $\mathrm{nm}$ ve 108-46 nm aralıklarında değiştiği hesaplandı. Bu sonuçlara göre bor katkı oranına bağlı olarak birbirlerine oldukça yakın olan kristalit boyutunun azaldığı görüldü ve benzer değişimler AFM analizlerinde de görülmektedir. Hesaplanan bu değerler daha önce saf, Ag ve Zn ile katkılanmış InSe kristalleri için yapılan çalışmalarla uyum içerisindedir (Gürbulak ve ark., 2014; Gürbulak ve ark., 2016). Ayrıca, bu kristaller için daha önce XRD analizlerinden yapılan hesaplamalarda kristalit boyutunun saf 
InSe tek kristaline oranla bor katkılı InSe tek kristallerinde katkı oranına bağlı olarak azaldığı görüldü (Ertap ve Karabulut, 2019). Saf, \% 0.1 ve \% 0.5 bor katkılı InSe tek kristallerinin yüzey pürüzlülügünün çok az olduğu ve kristallerin ampulün keskin ucundan (büyütme ampulünün sivri kısmı) doğru büyüdüğü görülmektedir ve yüzey pürüzsüzlüğünün değişimi AFM ölçümlerin elde edilen sonuçlarda da görülmektedir. InSe tek kristalinin tabakalı yapısında tabakaların paketlenmesinden veya büyütme sürecinden kaynaklanan dislokasyonların olduğu bilinmektedir. Genellikle, stokiyometrik eriyikten büyütülen InSe tek kristallerinin $c$ ekseni büyütme ampulünün eksenine dik olmaktadır. Saf, \% 0.1 ve \% 0.5 bor katk1lı InSe tek kristallerinin SEM görüntülerinin analizleri bu bilgileri doğrulamakta ve bu sonuçlar daha önce yapılan çalışmalar ile uyum içerisindedir (Blasi ve ark., 1982; Blasi ve ark., 1985; Blasi ve ark., 1989; Balitskii, 2006; Mustafa ve ark., 2010; Siciliano ve ark., 2011). InSe tek kristalleri için yapılan SEM analizleri sonucunda geniş yüzeyli mükemmel bölgeli InSe tek kristallerinin stokiyometrik eriyikten büyüdüğü belirtilmiştir (Blasi ve ark., 1982; Blasi ve ark., 1989). SEM ölçümlerinden elde edilen görüntülerde katk1lı numunelerin yüzeylerinde değişimler olduğu görülmektedir. Bu değişimlerin, büyütülen tek kristallerin büyütülme koşulları, katkı oranı ve eklenen safsızlıklardan kaynaklanmaktadır.

Saf, \% 0.1 ve \% 0.5 bor katkılı InSe tek kristallerinin optik soğurma ölçümleri oda sıcaklığında $(300 \mathrm{~K})$ yapıldı ve optik soğurma spektrumlarından elde edilen grafikler sırasıyla Şekil 7, Şekil 8 ve Şekil 9'da verilmektedir.
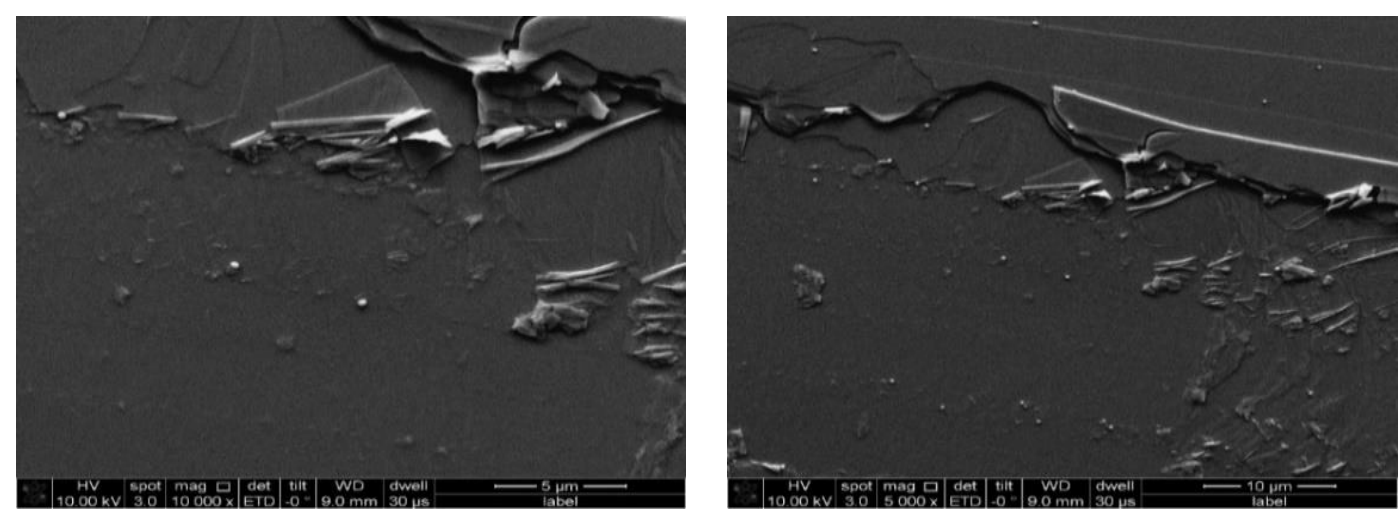

Şekil 4. Saf InSe tek kristalinin SEM görüntüleri.
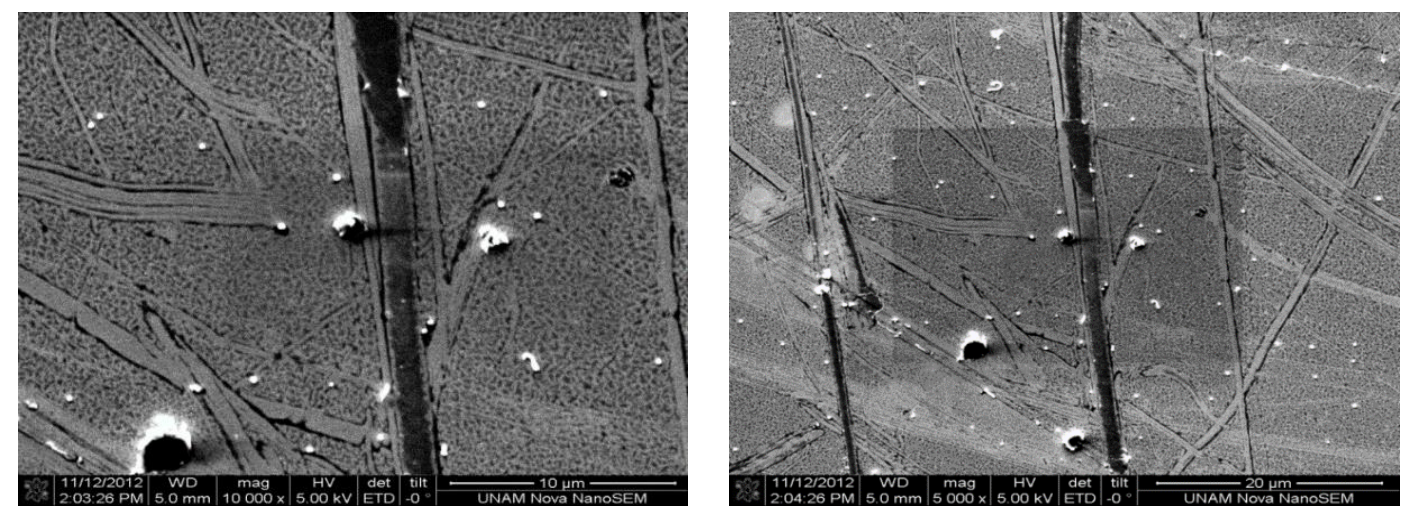

Şekil 5. \% 0.1 bor katkılı InSe tek kristalinin SEM görüntüleri. 

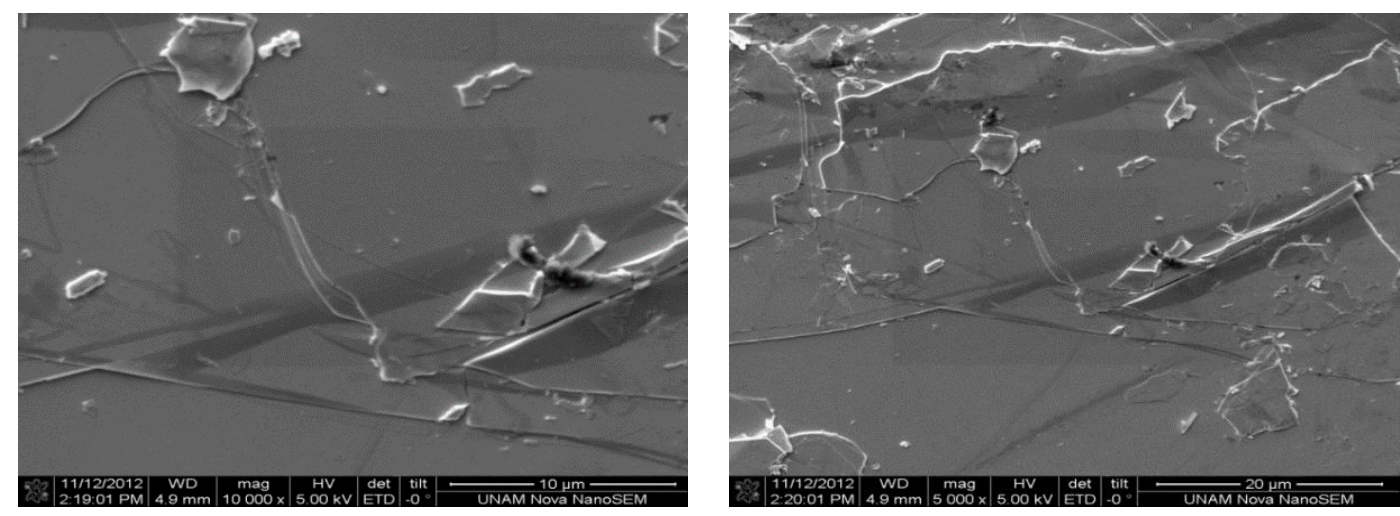

Şekil 6. \% 0.5 bor katkılı InSe tek kristalinin SEM görüntüleri.

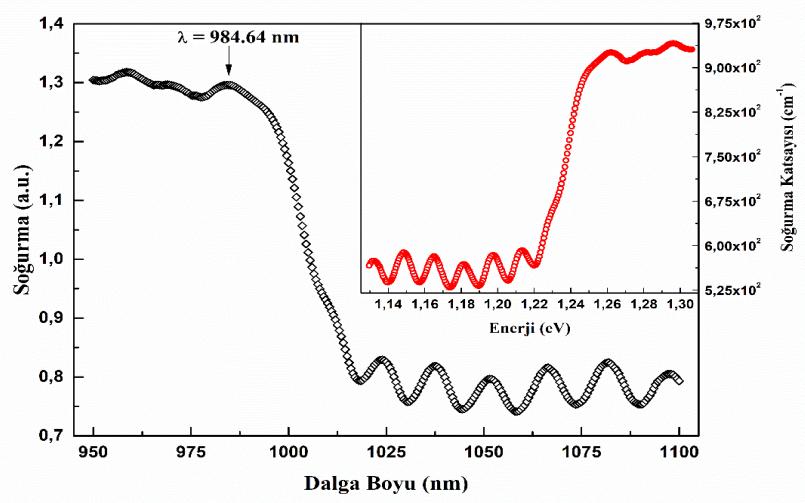

Şekil 7. Saf InSe tek kristalinin optik soğurma spektrumu.

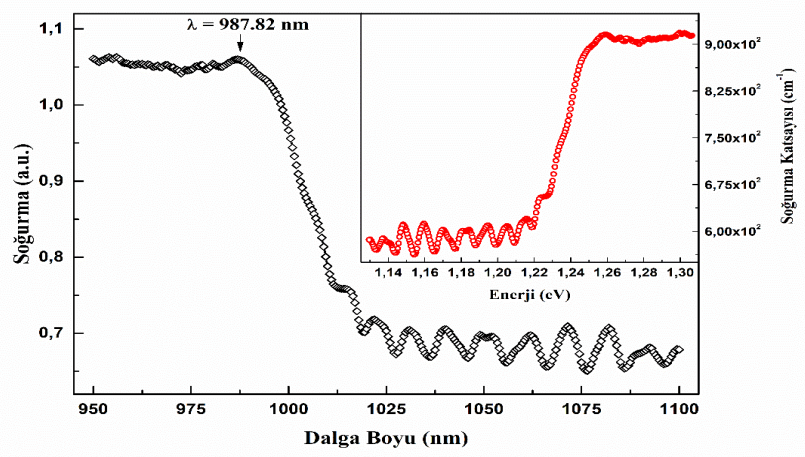

Şekil 8. \% 0.1 bor katk1lı InSe tek kristalinin optik soğurma spektrumu.

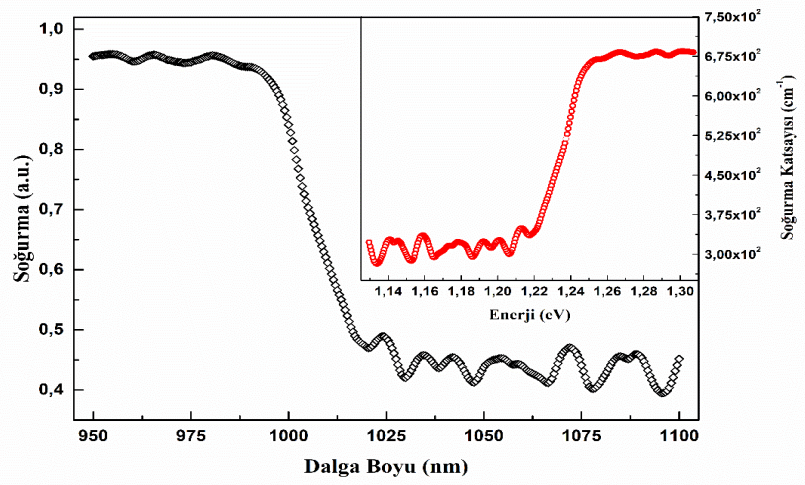

Şekil 9. \% 0.5 bor katk11ı InSe tek kristalinin optik soğurma spektrumu. 
Şekil 7 ve Şekil 8'den görüldüğü gibi saf ve \% 0.1 bor katkılı InSe tek kristallerine ait optik soğurma spektrumlarında sırasıyla $984.64 \mathrm{~nm}$ ve $987.82 \mathrm{~nm}$ dalga boylarında gözlenen pikler eksiton pikleridir. Saf ve \% 0.1 bor katkılı InSe tek kristallerinin optik soğurma spektrumlarında eksiton pikleri net olarak gözlenirken \% 0.5 bor katk1lı InSe tek kristalinin optik soğurma spektrumunda ise eksiton pikinin tam olarak kaybolmamakla birlikte genişlediği görülmektedir. Saf ve \% 0.1 bor katkılı InSe tek kristallerindeki bu eksiton durumu iletim bandının hemen altında bulunmaktadır. Literatürden InSe tek kristallerinde direkt serbest eksiton bağlanma enerjisinin $14.5 \mathrm{meV}$ (Camassel ve ark., 1978) olduğu bilinmektedir. Saf ve \% 0.1 bor katkılı InSe tek kristalleri için eksiton bağlanma enerjisi dikkate alındığında oda sıcaklığındaki yasak enerji bant aralıkları sırasıyla $1.274 \mathrm{eV}$ ve $1.270 \mathrm{eV}$ olarak hesapland1. Saf ve \% 0.1 bor katkılı InSe tek kristallerinden farklı olarak \% 0.5 bor katk1lı InSe tek kristalinde eksiton durumu oda sıcaklığında genişlediğinden bantlararası geçiş durumu gerçekleşmektedir. Şekil 9'un analizden \% 0.5 bor katkı1ı InSe tek kristalinin $1016 \mathrm{~nm}$ dalga boyuna denk gelen soğurma kenarına sahip olduğu görülmektedir. \% 0.5 bor katkılı InSe tek kristalinin bu dalga boylarından daha düşük dalga boylarındaki ışığı şiddetli bir şekilde soğurduğu görülmektedir. Bundan dolayı, \% 0.5 bor katkılı InSe tek kristalinin temel bant aralığının hemen altındaki foton enerjilerinde güçlü soğurma olduğu gözlemlenir. Bu durum, \% 0.5 bor katk1lı InSe tek kristalinin $1016 \mathrm{~nm}$ dalga boylarından daha düşük enerjili ışınları, değerlik bandındaki elektronları iletim bandının üstüne (rezonans durumu) uyaracağı anlamına gelmektedir. İşte bu soğurma bant kenarı, eksiton pikinin genişlediği \% 0.5 bor katkılı InSe tek kristalinde yasak enerji bant aralığı değerini göstermektedir. Bu bilgilerden yola çıkarak \% 0.5 bor katkılı InSe tek kristalinin oda sıcaklığındaki yasak enerji bant aralığı $1.222 \mathrm{eV}$ olarak hesapland. Saf, \% 0.1 ve \% 0.5 bor katkılı InSe tek kristallerinde soğurma valans bandından iletim bandına direkt geçişlerle olduğundan bu çalışmada kullanılan bütün tek kristaller direkt yasak enerji bant aralığına sahiptirler. Bu çalışmada incelenen InSe tek kristalleri için bulunan yasak enerji bant aralıkları literatürde InSe kristalleri için verilen değerlerle uyumludur (Blasi ve ark., 1983; Shigetomi ve Ikari, 2003; Deniz, 2004). Saf ve azot (N) implante edilmiş numunelerde direkt yasak enerji bant aralığı her iki numune için de $1.22 \mathrm{eV}$ olarak verilmiştir (Deniz, 2004). Genel olarak literatürde InSe tek kristali için yasak enerji bant aralığ değeri 1.2-1.3 eV civarında verilmiştir. Hesaplanan yasak enerji bant aralığı değerleri $1.2 \mathrm{eV}$ (Di Giulio ve ark., 1983), $1.24 \mathrm{eV}$ (Likforman ve ark., 1975), $1.29 \mathrm{eV}$ (Ateş, 2002), $1.3 \mathrm{eV}$ (Sreekumar ve ark., 2006) ve $1.3 \mathrm{eV}$ (Segura ve ark., 1983) olarak belirtilmiştir. Kalay (Sn) katkılı InSe kristali üzerine yapılan çalışmada, Sn atomunun yarıçapının In ve Se atomlarının yarıçapından büyük olmasından dolayı örgü parametrelerini genişlettiğini ve böylece yasak enerji bant aralığı değerinin arttığı belirtilmiştir (Duman, 2006). InSe tek kristaline oranla bor katkı oranına bağlı olarak katkılı InSe tek kristallerinin yasak enerji bant aralığı değerlerinin azaldığ görüldü. Bor katkılı InSe tek kristallerinde görülen kaymalar örgü kusurlarına paralel olarak bor atomlarının örgüdeki konumuna etkisi ile ilgilidir. Küçük iyonik yarıçaplı bor ( $\mathrm{r}_{\mathrm{B}}=0.41 \AA$ ) atomlarının tetragonal bağda daha büyük iyonik yarıçaplı In $\left(\mathrm{r}_{\mathrm{In}}=0.94 \AA\right.$ ) $)$ ile yer değiştirmesinden dolayı kristalin örgü deformasyon potansiyelinde bir değişim gerçekleştirebilir. Bor katkılı InSe tek kristalleri için hesaplanan yasak enerji bant aralığı değerlerindeki azalma ise katkılanan bor atomlarının yarıçapının In ve Se $\left(r_{S e}=0.64 \AA\right)$ atomlarının yarıçap değerlerinden küçük olması ve bu nedenle örgü parametrelerinin küçülmesi ile açıklanabilir.

InSe tek kristali için deneysel sonuçlardan hesaplanan ve literatürde verilen yasak enerji bant aralığı değerlerinin bu şekilde değişmesi, büyütme koşullarına bağlı olarak kristallerin farklı oranlarda safsızlık ve kusur seviyeleri içerdiğini göstermektedir. Genel olarak bir tek kristalin oda sıcaklığında ölçülen soğurma spektrumunda eksiton pikinin gözlemlenmesi ölçümü yapılan kristalin kalitesinin bir göstergesi olarak kabul edilmektedir. Büyütülen saf ve \% 0.1 bor katk1lı InSe tek kristallerinde eksiton 
piki görülmekle birlikte \% 0.5 bor katkı1ı InSe tek kristalinde de bu eksiton pikinin tamamen kaybolmamakla birlikte genişlemesi büyütülen saf, \% 0.1 ve $\% 0.5$ bor katkılı InSe tek kristallerinin kalitesini göstermektedir. Aynı kalınlıktaki saf ve bor katkılı InSe tek kristallerinin optik soğurma spektrumlarının analizlerinden, \% 0.1 ve \% 0.5 bor katkılı InSe tek kristallerinin katkılama oranına bağlı olarak soğurma katsayısının ve soğurma şiddetinin saf InSe tek kristaline oranla zayıfladığı (azaldığı) hesaplamalardan ve çizilen grafiklerden açıkça görülmektedir. Genellikle oda sıcaklığı ve yüksek sıcaklıklarda fonon-fonon ve fonon-elektron etkileşmeleri oldukça yoğundur ve bundan dolayı eksiton durumlarının gözlenmesi zordur. Eksitonların gözlenememesinin nedeni ise eksitonların fononlarla çarpışmalarıdır. Yüksek sıcaklıklarda çarpışma ihtimali artacağından eksitonların ömrü kısalacak ve böylece soğurma spektrumunda eksiton pikinin genişlemesi sonucu ortaya çıkacaktır. Ancak oda sıcaklığında bile büyütülen saf ve \% 0.1 bor katkılı InSe tek kristallerinde eksiton piki net olarak görülmektedir. Ayrıca, \% 0.5 bor katkılı InSe tek kristalinde soğurma kıyısının uzun dalga boyuna doğru kaydığı ve eksiton pikinin tamamen kaybolmamakla birlikte genişlediği gözlemlendi. Bu kaymalar da eksiton-fonon ve eksiton-kusur etkileşmesi ile açıklanmaktadır.

Ayrıca, saf, \% 0.1 ve \% 0.5 bor katkılı InSe tek kristallerinin soğurma spektrumlarında da 1100$1025 \mathrm{~nm}$ dalga boyu aralığında görülen pikler, girişim çiftlerinin maksimumları ve minimumları olarak bilinmektedir (Blasi ve ark., 1983). Yüksek kalitede büyütülmüş tabakalı tek kristallerde eksitonun düşük enerji kuyruğunda girişim çiftleri açıkça gözlemlenir. Girişim çiftlerinin gözlemlendiği tek kristallerde maksimum ve minimumlar kolayca tayin edilebilir. Bu yöntem bantlararası geçiş aralığında kullanılabilir ancak eksiton bölgesinde uygulanamaz. Girişim çiftinin oluşması için incelenen tek kristalin büyük kırılma indisi ve eksiton bölgesine oranla düşük soğurma katsayısına sahip olması gerekmektedir. İncelenen kristaldeki dahili çatlaklar veya düzensiz kalınlık gibi kusurlar kırınımda $\lambda$ 'nın tekrarlanmasında ve genliğinde düzensizlikler oluşturur (Antonioli ve ark., 1977). Saf InSe tek kristalinin soğurma spektrumundan görüldüğü gibi \% 0.1 ve \% 0.5 bor katkılı InSe tek kristallerinin soğurma spektrumlarında da girişim çiftlerinin maksimumları ve minimumları görülmektedir. InSe tek kristallerinde bor katkı oranına bağlı olarak soğurma spektrumlarında gözlenen girişim çiftlerindeki bozulma olayı daha fazla olmaktadır. Bu girişim çiftleri saf InSe tek kristalinde net olmak üzere ve \% 0.1 ve $\% 0.5$ bor katkılı InSe tek kristallerinde gözlenmesi bir kez daha büyütülen kristallerin kalitesini göstermektedir.

\section{SONUÇ}

Bu çalışmada, Bridgman tekniği ile büyütülen saf, $\% 0.1$ ve $\% 0.5$ bor katkılı InSe tek kristallerinin morfolojik ve optik özellikleri araştırıldı. Saf, \% 0.1 ve \% 0.5 bor katkı1ı InSe tek kristallerinin AFM görüntülerinde tepe ve çukurların az olması büyütülen bütün tek kristallerin kalitesini, politipizmden kaynaklanan kusurların ve örgü kusurlarının az olduğunu göstermektedir. Yapılan SEM analizleri sonucunda saf, \% 0.1 ve \% 0.5 bor katkılı InSe tek kristallerinin birbirlerine oldukça yakın olan kristalit boyutları sırasıyla 140-62 nm, $120-58 \mathrm{~nm}$ ve $108-46 \mathrm{~nm}$ olarak hesaplandı ve benzer sonuçlar AFM analizlerinde de görüldü. Saf, \% 0.1 ve $\% 0.5$ bor katkılı InSe tek kristallerinin çok az yüzey pürüzü olmakla birlikte genelde pürüzsüz olduğu ve kristallerin ampulünün sivri kısmından büyüdüğü görülmektedir. SEM analizleri sonucunda geniş yüzeyli mükemmel bölgeli saf ve bor katkı1ı InSe tek kristallerinin stokiyometrik eriyikten büyüdüğü görüldü. Saf, \% 0.1 ve \% 0.5 bor katkılı InSe tek kristallerinin optik soğurma ölçümleri oda sıcaklığında gerçekleştirildi ve bütün tek kristallerin yasak enerji bant aralığı değerleri hesaplandı. Optik soğurma ölçümlerinden saf ve \% 0.1 bor katkılı InSe tek kristallerinde eksiton pikinin net olarak görüldüğü ancak, \% 0.5 bor katk1lı InSe tek kristalinde eksiton pikinin genişlediği gözlendi. Saf, \% 0.1 ve \% 0.5 bor katk1lı InSe tek kristallerinin yasak enerji bant 
aralığı değerleri sirasıyla $1.274 \mathrm{eV}, 1.270 \mathrm{eV}$ ve $1.222 \mathrm{eV}$ olarak hesaplandi. Hesaplanan yasak enerji bant aralıklarından görüldüğü gibi katkı oranı arttıkça soğurma kıyısı uzun dalga boyuna kaydığı ve yasak enerji bant aralığg değerinin azaldığı görüldü.

\section{TEŞEKKÜR}

Bu çalışma, Kafkas Üniversitesi Bilimsel Araştırma Projeleri Koordinatörlüğü tarafından 2012FEF-05 proje numarası ile desteklenmiştir.

\section{Çıkar Çatışması}

Makale yazarları aralarında herhangi bir çıkar çatışması olmadığını beyan ederler.

\section{Yazar Katkısı}

Yazarlar makaleye eşit oranda katkı sağlamış olduklarını beyan eder.

\section{KAYNAKLAR}

Antonioli G, Bianchi D, Canevari V, Emiliani U, Podini P, 1977. Optical constants of GaSe at the fundamental absorption edge. Physica Status Solidi (b), 81(2): 665-670.

Asabe MR, Chate PA, Delekar SD, Garadkar KM, Mulla IS, Hankare PP, 2008. Synthesis and characterization of chemically deposited indium selenide thin films at room temperature. Journal of Physics and Chemistry of Solids, 69: 249-254.

Ateş A, 2002. InSe ve InSe:Ho Tek Kristallerinin Büyütülmesi, Sicaklığa Bağlı Elektriksel ve Optik Özelliklerinin İncelenmesi. Atatürk Üniversitesi Fen Bilimleri Enstitüsü, Doktora Tezi (Basılmış).

Ateş A, Gürbulak B, Yıldırım M, Doğan S, 2003. Electric field influence on absorption measurement in InSe single crystal. Physica E, 16(2): 274-279.

Bacığlu A, Ertap H, Karabulut M, Mammedov GM, 2014. Sub-bandgap analysis of boron doped InSe single crystals by constant photocurrent method. Optical Materials, 37: 70-73.

Bakhtinov AP, Kovalyuk ZD, Sydor ON, Katerinchuk VN, Lytvyn OS, 2007. Formation of nanostructure on the surface of layered InSe semiconductor caused by oxidation under heating. Physics of the Solid State, 49(8): 1572-1578.

Balitskii OA, Savchyn VP, Jaeckel B, Jaegermann W, 2004. Surface characterization of $\mathrm{In}_{4} \mathrm{Se}_{3}$ single crystals. Physica E, 22: 921-923.

Balitskii OA, 2006. Self-organised nanostructures, obtained by oxidation of III-VI compounds. Materials Letters, 60: 594-599.

Blasi CDe, Micocci G, Rizzo A, Tepore A, 1982. Large InSe single crystals grown from stoichiometric and nonstoichiometric melts. Journal of Crystal Growth, 57: 482-486.

Blasi CDe, Micocci G, Mongelli S, Tepore A, Zuanni F, 1983. Growth and characterization of high quality InSe single crystals. Materials Chemistry and Physics, 9(1-3): 55-64.

Blasi C De, Manno D, Mongelli S, 1985. The stacking of polytypes in InSe crystals. Physica Status Solidi (a), 90(1): K5.

Blasi CDe, Drigo AV, Micocci G, Tepore A, 1989. Preparation and characterization of $\operatorname{In}_{2} \mathrm{Se}_{3}$ crystals. Journal of Crsytal Growth, 94: 455-458.

Blasi CDe, Manno D, Rizzo A, 1990. Study of the polytypism in melt grown InSe single crystals by convergent beam electron diffraction. Journal of Crystal Growth, 100: 347-353.

Camassel J, Merle P, Mathieu H, Chevy A, 1978. Excitonic absorption edge of indium selenide. Physical Review B, 17(12): 4718-4725.

Chevy A, Kuhn A, Martin MS, 1977. Large InSe monocrystals grown from a non-stoichiometric melt. Journal of Crystal Growth, 38: 118-122.

Chevy A, Gouskov A, Besson JM, 1978. Growth of crystalline slabs of layered InSe by the Czochralski method. Journal of Crystal Growth, 43: 756-759. 
Chevy A, 1981. Growth of indium selenides by vapour phase chemical transport; polytypism on indium monoselenide. Journal of Crystal Growth, 51: 157-163.

Cingolani A, Cingolani R, Ferrara M, Lugara M, 1985. Excitons and electron-hole plasma in InSe. Solid State Communications, 55(11): 1007-1010.

Deniz D, 2004. Growth and Characterization of InSe Single Crystals. Ortadoğu Teknik Üniversitesi Fen Bilimleri Enstitüsü, Yüksek Lisans Tezi (Basılmış).

Di Giulio M, Micocci G, Rizzo A, Tepore A, 1983. Photovoltaic effect in gold-indium selenide Schottky barriers. Journal of Applied Physics, 54: 5839-5843.

Duman S, 2006. n-InSe ve n-InSe:Sn Tek Kristallerinin Yasak Enerji Aralı̆̆ına Elektrik Alanın Etkisi ve nInSe:Sn Yarriletkeninin Schottky Kontak Davranışı. Atatürk Üniversitesi Fen Bilimleri Enstitüsü, Doktora Tezi (Basılmış).

Emery JY, Brahimotsmane L, Jouanne M, Julien C, Balkanski M, 1989. Growth conditions of $\operatorname{In}_{x} \mathrm{Se}_{\mathrm{y}}$ films by molecular beam deposition. Materials Science and Engineering B, 3: 13-17.

Ertap H, Mamedov GM, Karabulut M, Bacioglu A, 2011. Pool-Frenkel thermoelectric modulation of excition photoluminescence in GaSe crystals. Journal of Luminescence, 13: 1376-1379.

Ertap H, Bacioğlu A, Karabulut M, 2015. Photoluminescence properties of boron doped InSe single crystals. Journal of Luminescence, 167: 227-232.

Ertap H, Baydar T, Yüksek M, Karabulut M, 2016. Structural and optical properties of gallium sulphide thin film. Turkish Journal of Physics, 40(3): 297-303.

Ertap H, 2018. Nonlinear absorption, SHG behavior and carrier dynamics of $\mathrm{Nd}$ and Pr doped GaSe single crystals. Optical Materials, 83: 99-103.

Ertap H, Karabulut M, 2019. Structural and electrical properties of boron doped InSe single crystals. Materials Research Express, 6(3): 035901.

Hirohata A, Moodera JS, Berera GP, 2006. Structural and electrical propereties of InSe polycrystalline films and diode fabrication. Thin Solid Films, 510: 247-250.

Ikari T, Shigetomi S, Koga Y, Shigetomi S, 1981. Photoluminescence properties of Zn doped InSe single crystals. Physica Status Solidi (b), 103(1): K81-K83.

Gopal S, Viswanathan C, Karunagaran B, Narayandass SK, Mangalaraj D, Yi J, 2005. Preparation and characterization of electrodeposited indium selenide thin films. Crystal Research Technology, 40: 557-562.

Gouskov A, Camassel J, Gouskov L, 1982. Growth and characterization of III-VI layered crystals like GaSe, GaTe, InSe, GaSe $e_{1-x} T_{x}$ and $\mathrm{Ga}_{x} \mathrm{In}_{1-\mathrm{x}} \mathrm{Se}$. Progress in Crystal Growth and Characterization, 5(4): 323-413.

Gürbulak B, Yıldırım M, Abay B, Tüzemen S, Alieva M, Yoğurtçu YK, 1998. Growth and optical properties of Ho doped n-type indium selenide. Physica Status Solidi (a), 168(2): 495-500.

Gürbulak B, Yıldırım, M, Ateş A, Doğan S, Yoğurtçu YK, 1999. Growth and temperature dependence of optical properties of Er doped and undoped n-type InSe. Japan Journal of Applied Physics, 38: 5133-5136.

Gürbulak B, 1999. Growth and optical properties of Dy doped n-type InSe single crystal. Solid State Communications, 109: 665-669.

Gürbulak B, 2004. Urbach tail and optical investigations of Gd doped and undoped InSe single crystals. Physica Scripta, 70(2-3): 197-201.

Gürbulak B, Şata M, Dogan S, Duman S, Ashkhasi A, Keskenler EF, 2014. Structural characterizations and optical properties of InSe and InSe:Ag semiconductors grown by Bridgman/Stockbarger technique. Physica E, 64: 106-111.

Gürbulak B, Ashkhasi A, Şata M, Özçelik FŞ, Duman S, 2016. Structural characterization of InSe:Zn binary semiconductor grown by Bridgman/Stockbarger technique. International Journal of Thales Natural Sciences, ISSN(print): 2149-5217, 18-28.

Khandozhko VA, Kudrynskyi ZR, Kovalyuk ZD, 2014. Influence of low-temperature annealing on the quality of InSe layer single crystals and characteristics of n-InSe-p-InSe heterojunctions. Fizika i Tekhnika Poluprovodnikov, 48(4): 564-569.

Kobbi B, Kesri N, 2004. Physico-chemical and electrical properties of InSe thin films. Vacuum, 75(2): 177-182. 
Lashkarev GV, Slynko VV, Kovalyuk ZD, Sichkovskyi VI, Radchenko MV, Aleshkevych P, Scymczak R, Dobrowolski W, Minikaev R, Zaslonkin AV, 2007. Anomalies of magnetic properties of layered crystals InSe containing Mn. Materials Science and Engineering C, 27: 1052-1055.

Likforman A, Carre D, Etienne J, Bachet B, 1975. Crystal structure of indium monoselenide (InSe). Acta Crystallographica B, 31: 1252-1254.

Mustafa FI, Gupta S, Goyal N, Tripathi SK, 2010. Effect of indium concertration on the electrical properties of InSe alloy. Physica B, 405: 4087-4091.

Olguin D, Canterero A, Ulrich C, Syassen K, 2003. Effect of pressure on structural properties and energy band gaps of $\gamma$-InSe. Physica Status Solidi (b), 235(2): 456-463.

Parlak M, Erçelebi Ç, Günal I, Salaeva Z, Allakverdiev K, 1995. Growth and characterization of polycrystalline InSe thin films. Thin Solid Films, 258: 86-90.

Pathan HM, Kulkarni SS, Mane RS, Lokhande CD, 2005. Preparation and characterization of indium selenide thin films from a chemical route. Materials Chemistry and Physics, 93: 16-20.

Rushchanskii KZ, 2004. The influence of hydrostatic pressure on the static and dynamic properties of an InSe crystal: A first-principles study. Physics of the Solid State, 46(1): 179-187.

Segura A, Guesdon JP, Besson JM, Chevy A, 1983. Photoconductivity and photovoltaic effect in indium selenide. Journal of Applied Physics, 54: 876-888.

Shigetomi S, Ikari T, 2003. Electrical and optical properties of $n$ - and p-InSe doped with Sn and As. Journal of Applied Physics, 93(4): 2301-2303.

Siciliano T, Tepore A, Micocci G, Genga A, Siciliano M, Filippo E, 2011. Synthesis and characterization of indium monoselenide (InSe) nanowires. Journal of Materials Science: Materials in Electronics, 22(6): 649653.

Sreekumar R, Kumar PMR, Kartha CS, Vijayakumar KP, Kabiraj D, Khan SA, Avasthi DK, 2006. SHI Induced Single-Phase InSe Formation at Lower Annealing Temperature. Nuclear Instruments and Methods in Physics Research B, 244: 190-193.

Uosaki K, Koinuma M, 1993. Atomic imaging of an InSe single-crystal surface with atomic force microscope. Journal of Applied Physics, 74(3): 1675-1678.

Viswanathan C, Gopal S, Thamilselvan M, Premnazeer K, Mangalaraj D, Narayandass Sa. K, Yi, J, Ingram DC, 2004. Space charge limited current, variable hopping and mobility gap in thermally evaporated amorphous InSe thin films. Journal of Materials Science: Materials in Electronics, 15: 787-792.

Yüksek M, Ertap H, Elmali A, Yaglioglu HG, Mamedov GM, Karabulut M, Özturk MK, 2012. Two photon absorption characteristics of bulk GaTe crystal. Optics and Laser Tecnology, 44: 2178-2181.

Zhirko Yu I, Kovalyuk ZD, Pyrlja MM, Boledzyuk VB, 2007. Application of layered InSe and GaSe crystals and powders for solid state hydrogen storage. Hydrogen Materials Science and Chemistry of Carbon Nanomaterials, 325-340. 